PEMBELAJAR: Jurnal Ilmu Pendidikan, Keguruan, dan Pembelajaran

Volume 3 Nomor 1 April 2019

e-ISSN: 2549-9114 dan p-ISSN: 2549-9203

(Received: Januari-2019; Reviewed: Maret-2019; Published: April 2019)

DOI : https://doi.org/10.26858/pembelajar.v3i1.6387

\title{
Analisis Perbedaan Pada Kurikulum KTSP Dan Kurikulum 2013 Terhadap Penyesuaian Alokasi Waktu Perminggu Untuk SDLB
}

\author{
Harizki Agung Nugroho ${ }^{a}$, Ishartiwi ${ }^{b}$, \\ ${ }^{a}$ Program Pasca Sarjana, Pendidikan Luar Biasa Universitas Negeri Yogyakarta. \\ Corresponding e-mail: harizkiagung@gmail.com
}

\begin{abstract}
Abstrak: Konsep kurikulum berkembang sejalan dengan perkembangan teori dan praktik pendidikan serta bervariasi sesuai dengan aliran atau teori pendidikan yang dianutnya. Menurut pandangan lama, sejak zaman Yunanni Kuno, kurikulum merupakan kumpulan mata pelajaran-mata pelajaran yang harus disampaikan guru atau dipelajari siswa. Pendidikan dalam sejarah peradaban anak manusia adalah salah satu komponen kehidupan yang paling urgent. Semenjak manusia berinteraksi dengan aktifitas pendidikan ini semenjak itulah manusia telah berhasil merealisasikan berbagai perkembangan dan kemajuan dalam segala lingkup kehidupan mereka. Bahkan pendidikan adalah suatu yang alami dalam perkembangan peradaban manusia. Kurikulum sering dibedakan antara kurikulum sebagai rencana (curriculum plan) dengan kurikulum yang fungsional (functioning curriculum). Kurikulum bukan hanya merupakan rencana tertulis bagi pengajaran, melainkan sesuatu yang fungsional yang beroperasi dalam kelas, yang memberi pedoman dan mengatur lingkungan dan kegiatan yang berlangsung di dalam kelas.
\end{abstract}

Kata Kunci: konsep kurikulum.

Abstract:The concept of curriculum develops in line with the development of educational theory and practice and varies according to the flow or theory of education it embraces. According to the old view, since the time of the Ancient Yunanni, the curriculum is a collection of subjects to be submitted by teachers or studied by students. Education in the history of civilization of the human child is one of the most urgent components of life. Since humans have interacted with these educational activities ever since, humans have succeeded in realizing various developments and progress in all spheres of their lives. Even education is a natural in the development of human civilization. The curriculum is often distinguished between the curriculum as a plan (curriculum plan) with a functional curriculum. The curriculum is not just a written plan for teaching, but something functional that operates in the classroom, which guides and regulates the environment and activities that take place in the classroom.

Keywords: The concept of curriculum.

(C)2019 -Pembelajar Universitas Negeri Makassar. Ini adalah artikel dengan akses terbuka dibawah licenci CC BY-NC-4.0 (https://creativecommons.org/licenses/by-nc/4.0/ ).

\section{PENDAHULUAN}

Pendidikan dalam sejarah peradaban anak manusia adalah salah satu komponen kehidupan yang paling urgent. Semenjak manusia berinteraksi dengan aktifitas pendidikan ini semenjak itulah manusia telah berhasil merealisasikan berbagai perkembangan dan kemajuan dalam segala lingkup kehidupan mereka. Bahkan pendidikan adalah suatu yang 
alami dalam perkembangan peradaban manusia. Secara paralel proses pendidikan pun mengalami kemajuan yang sangat pesat, baik dalam bentuk metode, sarana maupun target yang akan dicapai. Karena hal ini merupakan salah satu sifat dan keistimewaan dari pendidikan, yaitu selalu bersifat maju. Dan apabila sebuah pendidikan tidak mengalami serta tidak menyebabkan suatu kemajuan atau malah menimbulkan kemunduran maka tidaklah dinamakan pendidikan. Karena pendidikan adalah sebuah aktifitas yang integral yang mencakup target, metode dan sarana dalam membentuk manusia-manusia yang mampu berinteraksi dan beradabtasi dengan lingkungannya, baik internal maupun eksternal demi terwujudnya kemajuan yang lebih baik.

Dalam rangka meningkatkan mutu pendidikan Indonesia, pemerintah terus berupaya melakukan berbagai reformasi dalam bidang pendidikan. Dan sebagai sarana untuk meningkatkan mutu pendidikan diperlukan sebuah kurikulum. Menurut Sukmadinata (2008:5), "Kurikulum (curriculum) merupakan suatu rencana yang memberi pedoman atau pegangan dalam proses kegiatan belajar mengajar". Kurikulum dipahami sebagai seperangkat rencana dan pengaturan mengenai tujuan, isi, dan bahan pelajaran serta cara yang digunakan sebagai pedoman penyelenggaraan kegiatan pembelajaran untuk mencapai tujuan pendidikan tertentu. Kurikulum memiliki empat komponen, yaitu komponen tujuan, isi kurikulum, metode atau strategi pencapaian tujuan dan komponen evaluasi. Sebagai suatu sistem setiap komponen harus saling berkaitan satu sama lainnya. Manakala salah satu komponen yang membentuk sistem kurikulum terganggu atau tidak berkaitan dengan komponen lainnya, maka sistem kurikulum pun akan terganggu pula.

\section{METODE}

Penelitian ini merupakan penelitian analisis isi (content analysis). Analisis isi kuantitatif didefinisikan sebagai suatu teknik penelitian ilmiah yang ditujukan untuk mengetahui gambaran karakteristik isi dan menarik inferensi dari isi (Eriyanto, 2011: 15). Analisis isi pada penelitian ini bertujuan untuk menganalisis isi pada kurikulum KTSP dengan kurikulum K13 mengenai perbedaan alokasi watu pembelajaran di SDLB. Analisis dilakukan dengan mengidentifikasi keberadaan item-item dari masing-masing kurikulum dimana letak perbedaan alokasi pembelajarannya.

Objek penelitian yang diteliti pada penelitian ini adalah alokasi waktu pembelajaran di SDLB pada kurikulum KTSP dan K13.

Instrumen penelitian adalah alat yang digunakan untuk mengambil informasi dari objek atau subjek yang diteliti. Menurut Sukardi (2012: 121) suatu instrumen dikatakan valid jika instrumen yang digunakan dapat mengukur hal yang hendak diukur. Pada penelitian ini instrumen yang digunakan untuk mengumpulkan data berupa lembar observasi dalam bentuk check-list.

Pada penelitian ini, terdapat beberapa tahap dalam pengumpulan data, yaitu: Observasi dan Analisis konten (content analysis), terhadap alokasi waktu pembelajaran untuk SDLB pada masing-masingkurikulum KTSP dan K13.

Penelitian ini merupakan penelitian analisis deskriptif kualitatif sehingga data yang dimunculkan dan dianalisis.

\section{HASIL DAN PEMBAHASAN}

\subsection{Alokasi Waktu Pembelajaran Di SDLB Masing-Masing Kurikulum}

Tabel 1. Alokasi waktu pembelajaran di SDLB kurikulum KTSP

\begin{tabular}{|c|c|c|c|c|c|c|}
\hline \multirow[t]{2}{*}{$\begin{array}{c}\text { MATA } \\
\text { PELAJARAN }\end{array}$} & \multicolumn{6}{|c|}{$\begin{array}{l}\text { KELAS DAN ALOKASI } \\
\text { WAKTU PER } \\
\text { MINGGU UNTUK SD/MI } \\
\text { KURIKULUM KTSP }\end{array}$} \\
\hline & $\mathrm{I}$ & II & III & IV & $\mathrm{V}$ & VI \\
\hline \multicolumn{7}{|l|}{ Kelompok A } \\
\hline $\begin{array}{ll}1 & \text { Pendidikan } \\
\cdot & \text { Agama dan } \\
& \text { Budi Pekerti }\end{array}$ & 4 & 4 & 4 & 4 & 4 & 4 \\
\hline $\begin{array}{ll}2 & \text { Pendidikan } \\
\text {. } & \text { Pancasila dan } \\
& \text { Kewarganegar } \\
\text { an }\end{array}$ & 5 & 5 & 6 & 5 & 5 & 5 \\
\hline $\begin{array}{ll}3 & \text { Bahasa } \\
. & \text { Indonesia } \\
\end{array}$ & 8 & 9 & 10 & 7 & 7 & 7 \\
\hline 4 Matematika & 5 & 6 & 6 & 6 & 6 & 6 \\
\hline $\begin{array}{ll}5 & \text { IlmuPengetah } \\
\text {. uanAlam }\end{array}$ & - & - & - & 3 & 3 & 3 \\
\hline $\begin{array}{l}6 \text { IlmuPengetah } \\
\text {. uan Sosial }\end{array}$ & - & - & - & 3 & 3 & 3 \\
\hline
\end{tabular}




\begin{tabular}{|c|c|c|c|c|c|c|}
\hline \multicolumn{7}{|l|}{ Kelompok B } \\
\hline $\begin{array}{ll}1 & \text { SeniBudayada } \\
\text {. n Prakarya }\end{array}$ & 4 & 4 & 4 & 4 & 4 & 4 \\
\hline $\begin{array}{ll}2 \text { Pendidikan } \\
\text {. Jasmani, } \\
\text { Olahraga, } \\
\text { danKesehatan }\end{array}$ & 4 & 4 & 4 & 4 & 4 & 4 \\
\hline $\begin{array}{l}\text { Kelompok C } \\
\text { Program } \\
\text { Kebutuhan } \\
\text { Khusus*) } \\
\end{array}$ & & & & & & \\
\hline $\begin{array}{l}\text { Pengembanga } \\
\text { n Orientasi } \\
\text { dan Mobilitas }\end{array}$ & & & & 2 & 2 & 2 \\
\hline $\begin{array}{l}\text { Memuatan } \\
\text { lokal }\end{array}$ & & & & 2 & 2 & 2 \\
\hline $\begin{array}{l}\text { Pengembanga } \\
\text { n Diri }\end{array}$ & & & & 2 & 2 & 2 \\
\hline $\begin{array}{c}\text { JUMLAH } \\
\text { ALOKASI } \\
\text { WAKTU PER } \\
\text { MINGGU }\end{array}$ & 30 & 32 & 34 & 38 & 38 & 38 \\
\hline
\end{tabular}

Tabel 1.2 Alokasi waktu pembelajaran di SDLB kurikulum K13

\begin{tabular}{|c|c|c|c|c|c|c|c|}
\hline \multirow{2}{*}{\multicolumn{2}{|c|}{$\begin{array}{c}\text { MATA } \\
\text { PELAJARAN }\end{array}$}} & \multicolumn{6}{|c|}{$\begin{array}{l}\text { KELAS DAN ALOKASI } \\
\text { WAKTU PER } \\
\text { MINGGU UNTUK SDLB } \\
\text { KURIKULUM K13 }\end{array}$} \\
\hline & & I & II & III & $\begin{array}{l}\text { I } \\
\text { V }\end{array}$ & $\mathrm{V}$ & VI \\
\hline \multicolumn{8}{|c|}{ Kelompok A } \\
\hline $\begin{array}{l}1 \\
.\end{array}$ & $\begin{array}{l}\text { Pendidikan } \\
\text { Agama dan } \\
\text { Budi Pekerti }\end{array}$ & 4 & 4 & 4 & 4 & 4 & 4 \\
\hline $\begin{array}{l}2 \\
.\end{array}$ & $\begin{array}{l}\text { Pendidikan } \\
\text { Pancasila dan } \\
\text { Kewarganegara } \\
\mathrm{n}\end{array}$ & 4 & 4 & 4 & 4 & 4 & 4 \\
\hline $\begin{array}{l}3 \\
.\end{array}$ & $\begin{array}{l}\text { Bahasa } \\
\text { Indonesia }\end{array}$ & 6 & 6 & 8 & 6 & 6 & 6 \\
\hline 4 & Matematika & 4 & 4 & 4 & 4 & 4 & 4 \\
\hline 5 & $\begin{array}{l}\text { IlmuPengetahu } \\
\text { anAlam }\end{array}$ & - & - & - & 2 & 2 & 2 \\
\hline 6 & $\begin{array}{l}\text { IlmuPengetahu } \\
\text { anSosial }\end{array}$ & - & - & - & 2 & 2 & 2 \\
\hline \multicolumn{8}{|c|}{ Kelompok B } \\
\hline 1 & $\begin{array}{l}\text { SeniBudayadan } \\
\text { Prakarya }\end{array}$ & 5 & 7 & 7 & 7 & 7 & 7 \\
\hline
\end{tabular}

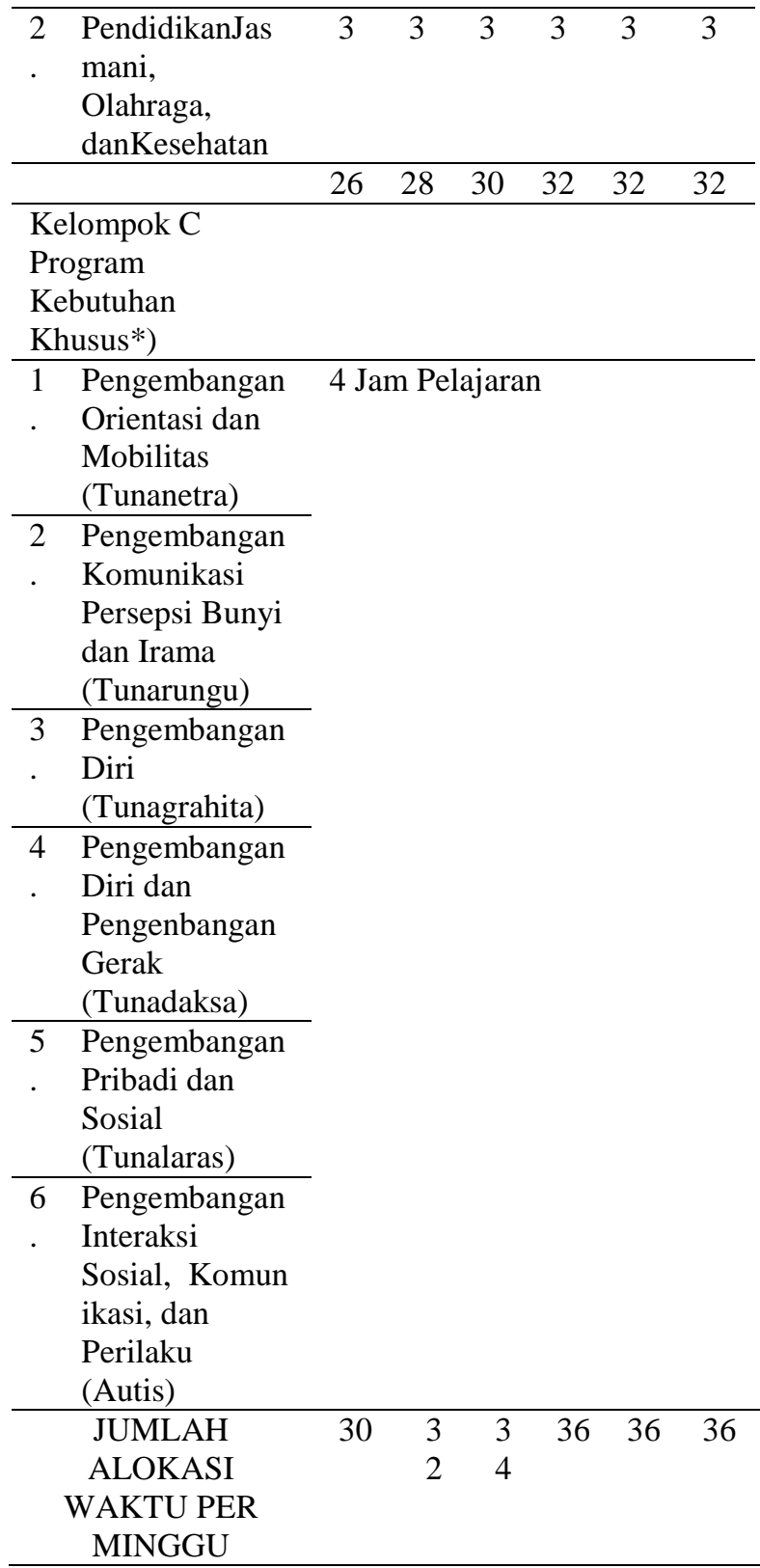

Program Kebutuhan Khusus dilakukan sebagai bentuk kompensasi atau penguatan akibat kelainan yang dialami Anak Berkebutuhan Khusus, dengan tujuan meminimalkan hambatan dan meningkatkan akses dalam mengikuti pendidikan dan pembelajaran yang lebih optimal. Program Kebutuhan Khusus bukan mata pelajaran, tetapi wajib diberikan sesuai dengan peserta didik berkebutuhan khusus. 


\subsubsection{Analisis Perbandingan Wakt Belajar Di SDLB Menurut Kedua Kurikulum}

Pada kurikulum KTSP mata pelajaran di SDLB hanya terbatas pada mata pelajaran dan muatan lokal saja, dimana pada kurikulum ini program kebutuhan khusus tidak mendapatkan alokasi jam pelajaran, yang mana artinya pada kurikulum KTSP program kebutuhan khusus ditiadakan.

Sedangkan pada kurikulum K13 program kebutuhan khusus masing-masingnya mendapatakan alokasi waktu pembelajran sebanyak Empat jam pelajaran, yang mana program kebutuhan khusus tersebut adalah, Pengembangan Orientasi dan Mobilitas (Tunanetra), Pengembangan Komunikasi Persepsi Bunyi dan Irama (Tunarungu), Pengembangan Diri (Tunagrahita), Pengembangan Diri dan Pengenbangan Gerak (Tunadaksa), Pengembangan Pribadi dan Sosial (Tunalaras), Pengembangan Interaksi Sosial, Komunikasi, dan Perilaku (Autis).

\subsubsection{Pergantian Nama Mata Pelajaran dari Kurikulum KTSP ke K13}

Tabel 1.3 nama matapelajaran di SDLB pada kurikulum KTSP

\begin{tabular}{cl}
\hline No & $\begin{array}{c}\text { Kelas Dan Alokasi Waktu Per Minggu } \\
\text { Untuk SDLB }\end{array}$ \\
\cline { 2 - 2 } & \multicolumn{1}{c}{ Kurikulum KTSP } \\
\cline { 2 - 2 } & \multicolumn{1}{c}{ Mata Pelajaran } \\
\hline 2 & Pendidikan Agama \\
\hline 3 & Pendidikan Kewarganegaraan \\
\hline 4 & Matematika \\
\hline 5 & Ilmu Pengetahuan Alam \\
\hline 6 & Ilmu Pengetahuan Sosial \\
\hline 7 & Seni Budaya Dan Keterampilan \\
\hline 8 & $\begin{array}{l}\text { Pendidikan Jasmani, Olahraga Dan } \\
\text { Kesehatan }\end{array}$ \\
\hline
\end{tabular}

Tabel 1.4 nama matapelajaran di SDLB pada kurikulum K13

\begin{tabular}{cl}
\hline No & \multicolumn{1}{c}{ Kelas Dan Alokasi Waktu Per Minggu } \\
& \multicolumn{1}{c}{ Kntuk SDLB } \\
\cline { 2 - 2 } & \multicolumn{1}{c}{ Mata Pelajaran } \\
\hline 1 & Pendidikan Agama Dan Budi Pekerti \\
\hline 2 & $\begin{array}{l}\text { Pendidikan Pancasila Dan } \\
\text { Kewarganegaran }\end{array}$ \\
\hline 3 & Bahasa Indonesia \\
\hline 4 & Matematika \\
\hline 5 & Ilmu pengetahuan alam \\
\hline 6 & Ilmu pengetahuan sosial \\
\hline 7 & Seni budaya dan prakarya \\
\hline 8 & Pendidikan jasmani, Olahraga, \\
& Dankesehatan \\
\hline
\end{tabular}

\subsubsection{Penyebab Perbedaan Jumlah Jam Pelajaran}

Adapun yang menyebabkan perbedaan jumlah jam pelajaran pada KTSP dan K13 adalah adanya perbedaan pada mata pelajaran pada tiap kurikulum, dimana pada K13 ada mata pelajaran yang dipecah menjadi Enam Mata pelajran yaitu program kebutuhan khusus, dimana tiap-tiap mata pelajaran mendapatkan alokasi sebanyak empat jam pelajaran.

\subsubsection{Pengembangan Dan Penghilangan Mata Pelajaran}

Pengembangan Orientasi Dan Mobilitas

(Tunanetra)

Pengembangan Komunikasi Persepsi Bunyi

Dan Irama (Tunarungu)

Pengembangan Diri (Tunagrahita)

Pengembangan Diri Dan Pengenbangan

Gerak (Tunadaksa)

Pengembangan Pribadi Dan Sosial

(Tunalaras)

Pengembangan Interaksi

Sosial, Komunikasi, Dan Perilaku (Autis)

Pada kurikulum KTSP ini pengembangan diri berbagai hambatan siswa dijadikan satu yaitu menjadi mata pelajaran "Program Khusus Orientasi dan Mobilitas" maka dari itu pada kurikulum KTSP ini tidak terdapat berbagai 
jenis mata pelajaran yang ada pada kolom tersebut.

Pada kurikulum K13

Muatan Lokal

Program Khusus Orientasi Dan Mobilitas

Pengembangan Diri

Pada kurikulum K13 ini tidak terdapat mata pelajaran "Program Khusus dan Orientasi Mobilitas" karena pada kurikulum ini mata pelajara tersebut dipecah menjadi sebanyak Enam mata pelajaran aga lebih jelas dan lebih fokus pada jenis hambatan yang dialami oleh siswa, adapun mata pelajarannnya yaitu:

Pengembangan Orientasi Dan Mobilitas (Tunanetra), Pengembangan Komunikasi Persepsi Bunyi Dan Irama (Tunarungu), Pengembangan Diri (Tunagrahita), Pengembangan Diri Dan Pengenbangan Gerak (Tunadaksa), Pengembangan Pribadi Dan Sosial (Tunalaras), Pengembangan Interaksi Sosial, Komunikasi, Dan Perilaku (Autis).

\section{KESIMPULAN}

Pada kurikulun KTSP dan kurikulum K13 hanya ada sedikit perbedaan saja, sebenarnya pada kedua kurikulum ini hanya berbeda pada jumlah mata belajaran yang disebabkan oleh adanya pemecahan mata pelajaran yang awalnya hanya Satu pada KTSP menjadi Enam pada K13.

Juga adanya perubahan nama pada setiap mata pelajaran pada K13, perubahan nama ini ada pada mata pelajaran pendidikan agama yang berubah menjadi pendidikan agama dan budi pekerti lalu pada mata pelajaran pendidikan kewarga negaraan yang menjadi pendidikan pancasila dan kewarga negaraan.

\section{DAFTAR PUSTAKA}

Arif, Soekardi. Sejarah Kurikulum Di Indonesia. 18 November 2015. http://belajarpknyuk.blogspot.com/2011/10/sejarahkurikulum-nasional-indonesia.html

Belen, S. 2010. Sejarah Kurikulum di Indonesia. Jakarta: Pusat Kurikulum Badan Penelitian dan Pengembangan

\author{
Kementerian Pendidikan Nasional \\ Jakarta.
}

Eriyanto, 2011. Analisis Isi: Pengantar Metodologi untuk Penelitian IlmuKomunikasi dan Ilmu-Ilmu Sosial Lainnya. Jakarta: Kencana Prenada Media Group.

Hidayati, Wiji. Pengembangan Kurikulum. 18 November 2015.

http://202.69.99.229/download/REALPAD/eStu dy/PDF/Paedagogis/Buku/Pengembang an\%20Kurukulum.pdf

Kredoanalisis. Hasil Analisis Tentang Perkembangan Kurikulum Sekolah Dasar (SD) dari masa colSonial hingga masa kurikulum 2013. 21 Agustus 2015.

https://kredoanalisis.wordpress.com/2015/01/17 /hasil-analisis-tentang-perkembangankurikulum-sekolah-dasar-sd-dari-masakolonial-hingga-masa-kurikulum-2013/

Poerwati. Sejarah Kurikulum. 19 November 2015.http://staff.uny.ac.id/sites/default/f iles/pendidikan/Poerwanti\%20Hadi\%20 Pratiwi,\%20S.Pd.,\%20M.Si./Sejarah_k urikulum.pdf.

Sukardi. 2013. Metodologi Penelitian Pendidikan Kompetensi dan Praktiknya. Jakarta : Bumi Aksara.

Sutisna.Sejarah Perkembangan Kurikulum. 18 November

2015.http://file.upi.edu/Direktori/FPBS/ JUR._PEND._BAHASA_DAERAH/19 7607312001121

ADE_SUTISNA/SEJARAH_PERKEMB._K URIKULUM.pdf

Tim Pengembang MKDP Kurikulum dan Pembelajaran. 2009. Kurikulum dan Pembelajaran. Bandung : Jurusan Kurikulum dan Teknologi Pendidikan, Fakultas Ilmu Pendidikan Universitas Pendidikan Indonesia. 